\title{
BODY SURFACE AREA AS A PREDICTOR OF AORTIC AND PULMONARY VALVE DIAMETER
}

Scott B. Capps, $\mathrm{MS}^{\mathrm{a}}$

Ronald C. Elkins, $\mathrm{MD}^{\mathrm{b}}$

David M. Fronk, MS
Background: Predicting cardiac valve size from noncardiac anatomic measurements would benefit pediatric cardiologists, adult cardiologists, and cardiac surgeons in a number of decision-making situations. Previous studies correlating valve size with body size have been generated with the use of fixed autopsy specimens, angiography, and echocardiography, but primarily in the young. This study examines the relation of body surface area to measurements of the left ventricular-aortic junction (aortic valve anulus diameter) and the right ventricular-pulmonary trunk junction (pulmonary valve anulus diameter) in 6801 hearts across a wide spectrum of ages.

Methods: From June 1985 to October 1998, cardiac valves from 6801 donated hearts were analyzed morphologically. Donor age was newborn to 59 years (mean $31 \pm 17$ years; median 32 years). Calculated body surface areas ranged from 0.18 to $3.55 \mathrm{~m}^{2}$. Aortic $(\mathrm{n}=4636)$ and pulmonary valve diameters $(n=5480)$ were measured from enucleated valves suitable for allograft transplantation. Mean valve sizes were computed for ranges in body surface area in $0.1-\mathrm{m}^{2}$ increments.

Results: For adult men (age $\geq 17$ years), the mean aortic valve diameter was $23.1 \pm 2.0 \mathrm{~mm}(\mathrm{n}=2214)$ and the mean pulmonary valve diameter was $26.2 \pm$ $2.3 \mathrm{~mm}(\mathrm{n}=2589)$. For adult women, the mean aortic valve diameter was 21.0 $\pm 1.8 \mathrm{~mm}(\mathrm{n}=1156)$ and the mean pulmonary valve diameter was $23.9 \pm 2.2$ $\mathrm{mm}(\mathrm{n}=1408)$. The mean indexed aortic valve area was $2.02 \pm 0.52 \mathrm{~cm}^{2} / \mathrm{m}^{2}$ and the pulmonary valve area $2.65 \pm 0.52 \mathrm{~cm}^{2} / \mathrm{m}^{2}$. Between $82 \%$ and $85 \%$ of the variability was explained by the size of the patient. Regression equations were developed both overall and separately for men and women, although the additional contribution of sex above that of body size was less than $1 \%$.

Conclusions: Aortic and pulmonary valve diameters are closely related to body size. Thus, body surface area, when used in conjunction with other clinically accepted evaluations, is a useful tool for estimating normal aortic and pulmonary valve size. (J Thorac Cardiovasc Surg 2000;119:975-82)
$\mathrm{P}$ redicting the normal dimensions of the left ventricular-aortic junction and right ventricular-pulmonary trunk junction is important to pediatric cardiol-

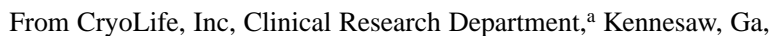
and Section of Thoracic and Cardiovascular Surgery, Department of Surgery, University of Oklahoma Health Sciences Center, ${ }^{b}$ Oklahoma City, Okla.

Received for publication Dec 31, 1999; revisions requested Jan 18, 2000; revisions received Feb 14, 2000; accepted for publication Feb 14, 2000.

Address for reprints: Ronald C. Elkins, MD, Thoracic Surgery, University of Oklahoma Health Sciences Center, PO Box 26901, Oklahoma City, OK 73190.

Copyright (C) 2000 by The American Association for Thoracic Surgery

0022-5223/2000 $\$ 12.00+0 \quad \mathbf{1 2 / 1 / 1 0 6 5 2 3}$

doi: $10.1067 / \mathrm{mtc} .2000 .106523$ ogists, adult cardiologists, and cardiac surgeons. ${ }^{1}$ In congenital heart disease, the information is useful in malformations that affect right ventricular or left ventricular outflow. In aortic valve disease, the disease process leading to valve replacement can alter the native anulus diameter, resulting in annular stenosis or dilatation. In these situations, an important issue is whether to adjust the size of the anulus to allow implantation of a "normal" sized valve or to use a replacement valve matching the diseased size (stenotic or dilated). If the anulus size requires surgical modification, for example, enlargement or reduction, anatomic guidelines are needed for determining how the diseased anulus should be resized.

Previous research studies have correlated valve size with anatomic variables (height, weight, age, sex, and 
Table I. Morphometric measurements and age

\begin{tabular}{|c|c|c|c|c|c|c|}
\hline \multirow[b]{2}{*}{ Anatomic variable } & \multicolumn{3}{|c|}{ Male donor $(n=4399)^{*}$} & \multicolumn{3}{|c|}{ Female donor $(n=2402)^{\dagger}$} \\
\hline & Range & Mean $\pm S D$ & Median & Range & Mean $\pm S D$ & Median \\
\hline Age (y) & $0-59$ & $30.8 \pm 16.8$ & 31.0 & $0-59$ & $30.9 \pm 17.4$ & 34.0 \\
\hline Height $(\mathrm{cm})$ & $28-221$ & $167.2 \pm 29.9$ & 178 & $30-206$ & $154.2 \pm 27.7$ & 163 \\
\hline Weight $(\mathrm{kg})$ & $3-227$ & $74.5 \pm 29.6$ & 77 & $3-205$ & $61.0 \pm 27.1$ & 60 \\
\hline $\operatorname{BMI}\left(\mathrm{kg} / \mathrm{m}^{2}\right)$ & 7.3-77.2 & $25.2 \pm 6.6$ & 24.5 & $6.0-79.3$ & $24.3 \pm 7.9$ & 22.7 \\
\hline $\operatorname{BSA}\left(\mathrm{m}^{2}\right)$ & $0.19-3.55$ & $1.85 \pm 0.53^{\ddagger}$ & 1.96 & $0.18-3.22$ & $1.60 \pm 0.48^{\ddagger}$ & 1.7 \\
\hline
\end{tabular}

$S D$, Standard deviation; BMI, body mass index; BSA, body surface area.

*AVD $(\mathrm{n}=2993)$, PVD $(\mathrm{n}=3508)$.

AVD $(\mathrm{n}=1643)$, PVD $(\mathrm{n}=1972)$.

$\stackrel{\square}{P}<.01$, comparison between male and female donors.

body surface area [BSA]). ${ }^{1-12}$ Despite differences in population base, sample size, specimen preparation and sizing method, ${ }^{1-6}$ and measurement technique (autopsy, ${ }^{1-7}$ angiography, ${ }^{8}$ echocardiography, ${ }^{9-11}$ and computed tomography, ${ }^{12}$ these studies have identified similar relations between growth of the body and size of the anuli. However, they have been sufficiently different quantitatively to warrant further study.

This study examines the relation of height, weight, age, sex, and BSA to the size of the aortic and pulmonary valve anuli in 6801 fresh hearts.

\section{Material and methods}

Study sample. From June 1985 to October 1998, 6801 human hearts were donated to process aortic and pulmonary allograft valves for transplantation (CryoLife, Inc, Kennesaw, $\mathrm{Ga}$ ). Incoming tissue was accepted on the basis of a comprehensive list of inclusion criteria, including donor age, no history of rheumatic fever, absence of endocarditis, no significant murmurs, no history of hypertension, no significant chest wall injuries, and negative serologic cultures. So that tissue viability would be maintained, hearts were recovered from qualified donors within 24 hours of asystole and were dissected within 52 hours of asystole. Information on height, weight, age, and sex was collected on each donor. Only donor hearts with a record of all 4 of these variables were included in the analysis.

Although each accepted heart may potentially provide one aortic and one pulmonary valve, some valves fall outside of CryoLife specifications because of tissue anomalies such as plaque, fenestrations, or structural abnormalities. Only enucleated valves suitable for homograft transplantation were incorporated in the analysis. Among the 6801 donated hearts, an aortic and pulmonary valve ( $\mathrm{n}=3315$ hearts), an aortic valve only ( $n=1321$ hearts), and a pulmonary valve only $(n=2165$ hearts) were processed. Thus, measurements from 4636 aortic and 5480 pulmonary heart valves were available for study.

Table I summarizes the morphometric data and ages of the study group. There were 4399 male and 2402 female subjects. Donor age ranged from newborn to 59 years (mean $30.8 \pm 16.8$ years in male subjects; mean $30.9 \pm 17.4$ years in female subjects). So that regression equations and mean values could be generated, measurements for 2993 aortic and 3508 pulmonary valves from male donors and 1643 aortic and 1972 pulmonary valves from female donors were included in the study.

BSA data were calculated by means of the multiple regression equation generated by Haycock, Schwartz, and Wisotsky ${ }^{13}$ and averaged $1.9 \pm 0.5 \mathrm{~m}^{2}$ (range 0.19-3.55 $\mathrm{m}^{2}$ ) in the male group and $1.6 \pm 0.5 \mathrm{~m}^{2}$ (range $\left.0.18-3.22 \mathrm{~m}^{2}\right)$ in the female group:

$$
\begin{aligned}
\text { BSA }\left(\mathrm{m}^{2}\right) & =0.024265 \times \text { Weight }(\mathrm{kg})^{0.5378} \\
\times & \text { Height }(\mathrm{cm})^{0.3964}
\end{aligned}
$$

Body mass index (BMI) was used as an indicator of obesity in the adult group, ranging from 7.3 to $77.2 \mathrm{~kg} / \mathrm{m}^{2}$ in the male group and 6.0 to $78.3 \mathrm{~kg} / \mathrm{m}^{2}$ in the female group ${ }^{10}$ :

$$
\text { BMI }\left(\mathrm{kg} / \mathrm{m}^{2}\right)=\text { Weight }(\mathrm{kg}) / \text { Height }^{2}\left(\mathrm{~m}^{2}\right)
$$

Valve sizing. The aortic and pulmonary valves were dissected from the heart and inspected for structural anomalies, and the internal anulus diameters for both the aortic (AVD) and pulmonary valves (PVD) were measured by inserting a Hegar uterine dilator in the valve without annular hyperextension. The Hegar dilators were graduated in 1-mm increments. Technicians are trained to measure the anulus diameter as accurately and consistently as possible. The tip of the dilator is inserted only to the level of the anulus and leaflet attachment. While the dilator is being inserted, the area where the artery and muscle band connect is gently squeezed. If this results in 1-mm (or less) folding of the external surface, the dilator size is the recorded anulus diameter. If there is a surface fold of more than $1 \mathrm{~mm}$, the next larger dilator size is tested, and if no fold is observed, the next smaller size is tested. The process is continued until the size of the dilator fills the valve, allowing for 1-mm folding or less.

Due to physiologic differences in the aortic and pulmonary anuli, PVD sizing is inherently difficult. The lack of resistance at the annular level when the Hegar dilator is being inserted may lead to measurement error, because it is difficult to avoid a stretching effect. The measurement error is estimated to be $\pm 1 \mathrm{~mm}$. 
Statistical analysis. All data are expressed as mean \pm 1 standard deviation (SD). The relationship of height, weight, age, and BSA to valve diameter was examined by means of regression analysis and curve estimation. The goodness-of-fit was evaluated by the coefficient of determination $\left(r^{2}\right) .^{14}$

Regression statistics were computed by means of several different models including linear, logarithmic, inverse, quadratic, and cubic, as well as the logarithmic transformation of a power equation. The model with the highest $r^{2}$ value was selected for use in predicting valve size. To account for valve diameter differences between analysis groups, the regression studies were stratified by sex, age (adult and pediatric), and valve type (AVD and PVD). Mean valve sizes were computed for BSA ranges in $0.1-\mathrm{m}^{2}$ increments. So that the relationship between AVD and PVD in normal hearts could be assessed, the valve types were also correlated by means of regression analysis and a paired $t$ test. A 1-way analysis of variance was used to assess differences in mean diameter between groups (sex and age). All statistical analyses were conducted with the SPSS 8.0.0 statistical software package (SPSS, Inc, Chicago, Ill).

\section{Results}

Mean valve size. For adult male donors (age $\geq 17$ years), the mean AVD was $23.1 \pm 2.0 \mathrm{~mm}(\mathrm{n}=2214)$ and the mean PVD was $26.2 \pm 2.3 \mathrm{~mm}(\mathrm{n}=2589)$. For adult female donors, the mean AVD was $21.0 \pm 1.8$ (n $=1156)$ and the mean PVD was $24.0 \pm 2.1 \mathrm{~mm}(\mathrm{n}=$ 1408). Indexing for BSA, the overall mean aortic valve index was $2.017 \pm 0.366 \mathrm{~cm}^{2} / \mathrm{m}^{2}$ and the mean pulmonary valve index was $2.652 \pm 0.502 \mathrm{~cm}^{2} / \mathrm{m}^{2}$.

Comparison of valve size by BSA. Variation in BSA between donors was addressed by tabulating mean valve diameter in $0.1-\mathrm{m}^{2}$ BSA increments. BSA ranges were subdivided by valve type and sex (Table II). Mean valve diameters were not reported for a BSA range if the sample size was 10 measurements or less.

Regression analysis: Valve diameter to anatomic variables. Five independent variables were used in the regression analysis to predict valve diameter for each valve type: age, height, weight, BMI, and BSA. The raw data were subdivided by sex. Table III lists the $r^{2}$ results of the sex-specific regressions among the 5 anatomic variables and annular valve size. Regression analyses relating BSA to valve size showed the best fit when applying a logarithmic transformation to BSA and valve size. In all 4 regression groups, the strongest association for the anatomic variables was BSA: $r^{2}=$ 85\%, AVD males; $r^{2}=83 \%$, AVD females; $r^{2}=84 \%$, PVD males; $r^{2}=82 \%$, PVD females. Height $\left(r^{2}=77 \%\right.$ to $79 \%)$ and age ( $r^{2}=69 \%$ to $\left.79 \%\right)$ were also strong predictors of valve diameter. BMI had the lowest $r^{2}$ $(23 \%$ to $28 \%)$.
Curve estimation: Valve diameter to BSA. The natural logarithmic transformation of the power function relation provided the best $r^{2}$ in the regression analysis of valve diameter and BSA. Performing least squares regression of $\ln$ (diameter) on $\ln (\mathrm{BSA})$, we estimate $b_{0}$ and $b_{1}$ in the equation:

$$
\ln (\text { Predicted diameter }[\mathrm{mm}])=\mathrm{b}_{0}+\mathrm{b}_{1} \cdot \ln (\mathrm{BSA})
$$

The results are shown in Table IV, and the prediction equation is of this form:

$$
\text { Predicted diameter }(\mathrm{mm})=\exp \left(\mathrm{b}_{0}+\mathrm{b}_{1} \cdot \ln [\mathrm{BSA}]\right)
$$

where the notation " $\exp (\mathrm{x})$ " indicates the mathematical constant $e$ raised to the $x t h$ power. These equations can be used to predict the valve diameter given the BSA, sex, and valve type (aortic or pulmonary). The Z-value (the number of standard deviation units from the mean normal value for similar BSA) of an observed dimension can be computed as follows:

$$
\mathrm{Z}=(\ln [\text { Observed diameter }]-\ln [\text { Predicted }
$$

Accounting for sex and valve type, Figs 1 and 2 show BSA plotted against the observed AVD and PVD with the fitted regression line and $95 \%$ confidence interval for each equation. As might be expected, there was a larger dispersion of the data in the higher BSA ranges, which corresponds to the adult population. Isolating data on aortic valve measurements, the regression equations predicted the AVD within $\pm 2 \mathrm{~mm}$ in $74 \%$ of the male group and in $75 \%$ of the female group. Increasing the range by $1 \mathrm{~mm}$, the model predicts the AVD within $\pm 3 \mathrm{~mm}$ in $89 \%$ and $90 \%$ of males and females, respectively.

Regression analysis: AVD to PVD. In addition to correlating valve diameter to BSA, the relationship between the aortic and pulmonary valves was analyzed. A total of 3315 donated hearts had both the aortic and pulmonary valve sized. By means of a paired $t$ test, the PVD value was larger than the AVD value for the male $(P<.001)$ and female $(P<.001)$ groups. The mean difference for males was $2.99 \pm 1.5 \mathrm{~mm}$ and for females $3.07 \pm 1.5 \mathrm{~mm}$. In 16 donors, the AVD was larger than the PVD. The mean ratio of AVD to PVD for the male and female groups was $0.87 \pm 0.059$ and $0.86 \pm 0.061$, respectively.

The results indicate a strong correlation between AVD and PVD in males $\left(r^{2}=0.90\right)$ and females $\left(r^{2}=\right.$ $0.88)$. The linear regression equations were as fol- 
Table II. Mean diameter results in BSA ranges*

\begin{tabular}{|c|c|c|c|c|c|c|c|c|}
\hline \multirow[b]{3}{*}{$B S A$ range $\left(m^{2}\right)$} & \multicolumn{4}{|c|}{ Male } & \multicolumn{4}{|c|}{ Female } \\
\hline & \multicolumn{2}{|c|}{$A V D(\mathrm{~mm})$} & \multicolumn{2}{|c|}{$P V D(\mathrm{~mm})$} & \multicolumn{2}{|c|}{$A V D(\mathrm{~mm})$} & \multicolumn{2}{|c|}{$P V D(\mathrm{~mm})$} \\
\hline & $n$ & Mean $\pm S D$ & $n$ & Mean $\pm S D$ & $n$ & Mean $\pm S D$ & $n$ & Mean $\pm S D$ \\
\hline $0.21-0.30$ & 19 & $8.8 \pm 1.0$ & 39 & $10.4 \pm 2.3$ & 20 & $9.1 \pm 0.8$ & 30 & $10.0 \pm 1.1$ \\
\hline $0.31-0.40$ & 34 & $10.0 \pm 1.6$ & 38 & $11.7 \pm 2.0$ & 30 & $9.9 \pm 0.8$ & 36 & $11.2 \pm 1.2$ \\
\hline $0.41-0.50$ & 57 & $11.2 \pm 0.9$ & 58 & $13.3 \pm 1.6$ & 32 & $11.4 \pm 1.4$ & 31 & $13.2 \pm 2.2$ \\
\hline $0.51-0.60$ & 64 & $12.3 \pm 1.2$ & 68 & $14.5 \pm 1.3$ & 50 & $11.9 \pm 1.2$ & 54 & $13.9 \pm 1.6$ \\
\hline $0.61-0.70$ & 70 & $13.5 \pm 1.3$ & 73 & $16.0 \pm 1.8$ & 35 & $12.5 \pm 1.3$ & 36 & $15.0 \pm 1.8$ \\
\hline $0.71-0.80$ & 57 & $14.1 \pm 1.1$ & 64 & $16.6 \pm 1.5$ & 31 & $13.9 \pm 1.5$ & 36 & $16.4 \pm 1.8$ \\
\hline $0.81-0.90$ & 37 & $14.6 \pm 1.5$ & 39 & $17.6 \pm 2.0$ & 30 & $14.3 \pm 1.3$ & 30 & $17.5 \pm 1.9$ \\
\hline $0.91-1.00$ & 48 & $15.6 \pm 1.3$ & 61 & $18.7 \pm 1.9$ & 32 & $15.4 \pm 1.4$ & 35 & $18.1 \pm 2.0$ \\
\hline $1.01-1.10$ & 42 & $16.3 \pm 1.5$ & 51 & $19.5 \pm 1.8$ & 30 & $15.6 \pm 1.4$ & 36 & $18.9 \pm 2.0$ \\
\hline $1.11-1.20$ & 42 & $17.2 \pm 1.9$ & 45 & $20.4 \pm 1.9$ & 21 & $16.8 \pm 1.8$ & 22 & $19.6 \pm 1.6$ \\
\hline $1.21-1.30$ & 25 & $17.1 \pm 1.6$ & 39 & $20.6 \pm 1.8$ & 23 & $17.8 \pm 2.1$ & 27 & $20.7 \pm 1.9$ \\
\hline $1.31-1.40$ & 38 & $18.7 \pm 1.7$ & 55 & $21.6 \pm 2.1$ & 47 & $18.5 \pm 2.2$ & 71 & $21.6 \pm 2.3$ \\
\hline $1.41-1.50$ & 39 & $19.1 \pm 2.3$ & 44 & $22.3 \pm 2.5$ & 122 & $19.6 \pm 2.0$ & 150 & $22.4 \pm 2.1$ \\
\hline $1.51-1.60$ & 52 & $20.7 \pm 2.4$ & 69 & $23.5 \pm 2.3$ & 175 & $19.9 \pm 1.9$ & 218 & $22.8 \pm 2.1$ \\
\hline $1.61-1.70$ & 125 & $20.8 \pm 2.1$ & 135 & $23.7 \pm 2.4$ & 267 & $20.5 \pm 1.8$ & 317 & $23.5 \pm 2.0$ \\
\hline $1.71-1.80$ & 223 & $21.5 \pm 2.0$ & 230 & $24.5 \pm 2.4$ & 218 & $21.0 \pm 1.6$ & 285 & $24.1 \pm 2.0$ \\
\hline $1.81-1.90$ & 350 & $22.3 \pm 2.1$ & 417 & $25.2 \pm 2.2$ & 148 & $21.3 \pm 1.6$ & 167 & $24.1 \pm 1.9$ \\
\hline $1.91-2.00$ & 466 & $22.6 \pm 1.7$ & 518 & $25.7 \pm 2.1$ & 109 & $21.5 \pm 1.4$ & 122 & $24.6 \pm 2.0$ \\
\hline $2.01-2.10$ & 453 & $23.0 \pm 1.8$ & 525 & $26.2 \pm 2.1$ & 77 & $21.6 \pm 1.4$ & 75 & $24.8 \pm 2.0$ \\
\hline $2.11-2.20$ & 266 & $23.6 \pm 1.9$ & 309 & $26.8 \pm 2.0$ & 46 & $21.9 \pm 1.5$ & 68 & $25.0 \pm 1.8$ \\
\hline $2.21-2.30$ & 172 & $23.8 \pm 1.8$ & 210 & $26.8 \pm 2.0$ & 31 & $21.8 \pm 1.5$ & 39 & $25.5 \pm 1.9$ \\
\hline $2.31-2.40$ & 115 & $24.1 \pm 1.9$ & 134 & $27.3 \pm 1.9$ & 25 & $22.0 \pm 1.5$ & 34 & $25.0 \pm 3.1$ \\
\hline $2.41-2.50$ & 85 & $24.4 \pm 1.9$ & 133 & $27.5 \pm 1.7$ & 11 & $22.5 \pm 1.6$ & 14 & $26.0 \pm 2.3$ \\
\hline $2.51-2.60$ & 43 & $24.8 \pm 1.8$ & 45 & $27.8 \pm 1.8$ & & & & \\
\hline $2.61-2.70$ & 33 & $25.2 \pm 2.3$ & 47 & $28.1 \pm 1.9$ & & & & \\
\hline
\end{tabular}

$A V D$, Aortic valve anulus diameter; $P V D$, pulmonary valve anulus diameter; $B S A$, body surface area; $S D$, standard deviation.

${ }^{*}$ Sample sizes of 10 diameter measurements or less are not reported.

lows: males, PVD $=2.489+1.025 \cdot$ AVD; females, $\mathrm{PVD}=1.740+1.071 \cdot$ AVD

\section{Comment}

The results of the current study are comparable with other studies in terms of the strongest predictor (BSA), mean diameter ranges, and the effect of age on the correlation outcome. Autopsy studies by Rowlatt, Rimoldi, and Lev, ${ }^{2}$ Kirklin and Barratt-Boyes, ${ }^{1}$ and Eckner and colleagues ${ }^{6}$ report a strong correlation between morphometric data and valve diameter. Studies by Scholz, ${ }^{4}$ Kitzman, ${ }^{5}$ and their associates also found a correlation between valve diameter and age. In a 1963 landmark study, Rowlatt, Rimoldi, and $\mathrm{Lev}^{2}$ related 21 cardiac dimensions to body weight, body length, age, and body area. The study population consisted of 83 normal hearts obtained at autopsy from children aged from birth to 15 years. Before measurement, the hearts were fixed in formalin. Using a logarithmic function, Rowlatt's group found a strong correlation of aortic $(r=0.95)$ and pulmonary $(r=0.94)$ valve circumference to BSA (square centimeters). Among the 4 variables analyzed, the relation was strongest for BSA. Circumference data predicted from the regression equations were mathematically transformed to valve diameter and tabulated in BSA ranges from $0.25 \mathrm{~m}^{2}$ to $2.0 \mathrm{~m}^{2}$. ${ }^{1}$ For similar BSA ranges, the results of the present study indicate higher mean diameters. For example, the mean AVD for a $1.0-\mathrm{m}^{2} \mathrm{BSA}$ was $13.9 \mathrm{~mm}$ as compared with $15.8 \mathrm{~mm}$ for a BSA range of 0.9 to $1.0 \mathrm{~m}^{2}$ in the current study. According to the predictive regression equation, the AVD for a male subject with a BSA of $1.0 \mathrm{~m}^{2}$ is $16.3 \mathrm{~mm}$.

Observed differences may involve the method of fixation, sample size, sample population, measurement method, and analysis method. The biggest difference in comparison with Rowlatt's study is the method of heart fixation (formalin-fixed vs fresh). Formalin fixation may cause shrinkage of valve tissue, yielding smaller diameter measurements than fresh tissue. ${ }^{15}$ This may partly explain the smaller mean diameters reported as compared with the present study. 
Table III. Association of AVD and PVD with age, height, weight, BMI, and BSA

\begin{tabular}{ccccc}
\hline & \multicolumn{2}{c}{ Male: $r^{2}(\%)$} & \multicolumn{2}{c}{ Female: $r^{2}(\%)$} \\
\cline { 2 - 3 } Anatomic variable & AVD $(n=2993)$ & $P V D(n=3508)$ & AVD $(n=1643)$ & $P V D(n=1972)$ \\
\hline Age $^{*}(\mathrm{y})$ & 79 & 74 & 79 & 69 \\
Height $(\mathrm{cm})$ & 79 & 79 & 89 & 77 \\
Weight $(\mathrm{kg})$ & 85 & 83 & 25 & 79 \\
BMI $\left(\mathrm{kg} / \mathrm{m}^{2}\right)$ & 28 & 28 & 83 & 23 \\
BSA $\left(\mathrm{m}^{2}\right)$ & 85 & 84 & 82 \\
\hline
\end{tabular}

$B M I$, Body mass index; $B S A$, body surface area; $A V D$, aortic valve anulus diameter; $P V D$, pulmonary valve anulus diameter; $r^{2}$, coefficient of determination as percent of variation explained.

*Only ages $>0$ were included in the analysis: $\mathrm{n}=2918, \mathrm{n}=3406, \mathrm{n}=1594, \mathrm{n}=1902$, respectively, for AVD male, PVD male, AVD female, and PVD female.

Table IV. Regression coefficients of valve anulus diameter $(\mathrm{mm})$ on $B S A\left(\mathrm{~m}^{2}\right)^{*}$

\begin{tabular}{cccccc}
\hline Structure & $n$ & Intercept $\left(b_{0}\right)$ & Slope $\left(b_{1}\right)$ & $S D$ & $r^{2}(\%)$ \\
\hline $\begin{array}{c}\text { Male } \\
\text { AVD }\end{array}$ & 2993 & $2.785 \pm 0.0025$ & $0.4777 \pm 0.0037$ & 0.08927 & 85 \\
PVD & 3508 & $2.936 \pm 0.0022$ & $0.4455 \pm 0.0032$ & 0.08835 & 84 \\
$\begin{array}{c}\text { Female } \\
\text { AVD }\end{array}$ & 1643 & & & & \\
PVD & 1972 & $2.769 \pm 0.0029$ & $0.4517 \pm 0.0050$ & 0.09293 & 83 \\
Total & & $2.913 \pm 0.0028$ & $0.4425 \pm 0.0047$ & 0.09563 & 82 \\
AVD & 4636 & $2.778 \pm 0.0019$ & $0.4727 \pm 0.0030$ & 0.09167 & 85 \\
PVD & 5480 & $2.926 \pm 0.0018$ & $0.4483 \pm 0.0027$ & 0.09179 & 84 \\
\hline
\end{tabular}

$A V D$, Aortic valve anulus diameter; $P V D$, pulmonary valve anulus diameter; $B S A$, body surface area; $S D$, standard deviation; $r^{2}(\%)$, percent of variation explained by each model.

*General form of the equation: predicted diameter $=\exp ($ intercept + slope $\cdot \operatorname{In}[\mathrm{BSA}])$.

Donor age is also a complicating factor when interpreting the results of previous studies. Pediatric data have generally been extrapolated to include older donors in the adult age group. ${ }^{1,4,8,11}$ There are strong correlations between valve size and age, height, weight, and/or BSA for children (age $<15$ years) associated with their rapid growth. The reported correlations in adults (age $\geq 15$ years) are weaker as growth changes are relatively small., 3,10 Two possible factors that may also affect anulus size in an adult population are the progressive increase in BMI and the increases in valve diameter with aging. $3,5,7,9,10,12$

Similar studies have been reported on the basis of measurements from angiography, ${ }^{8}$ echocardiography, ${ }^{9-11}$ and computed tomography. ${ }^{12}$ Roman and coworkers ${ }^{9}$ reported an echocardiography study relating aortic root dimensions to age, sex, and body habitus. The study population consisted of 52 children (age range 0-15 years) and 135 adults (age range 2074 years). In the children, aortic dimensions correlated with age and BSA with correlation coefficients slightly higher for BSA ( $r=0.90$ to $r=0.93$ ). The adult correlation between BSA and valve diameter was lower at $r=0.68$. As in the current analysis, BMI displayed the lowest correlation value for valve diameter. The current study was conducted on ex vivo as opposed to in vivo valves.

Not all studies found a correlation between BSA and valve diameter. Westaby and colleagues ${ }^{3}$ reviewed valve circumference data from 160 adult human hearts in the age range of 16 to 83 years. The mean age for this group was $58 \pm 13$ years. The hearts were formalin-fixed and the valve circumference data were transformed into valve diameters. The results of their multivariable analysis showed valve dimensions correlate poorly to body size variables, specifically BSA ( $r=$ 0.01 for aortic valves and $r=0.10$ for pulmonary valves). Fixation and age may have affected the results.

Several studies also reviewed the relationship between AVD and PVD. ${ }^{3-6}$ In the majority of studies, the pulmonary valve was found to be larger than the aortic valve. Westaby's group noted in their adult study that the PVD exceeds the AVD by a factor of 1.1. ${ }^{3}$ In the study on pediatric valves, Scholz and associates $^{4}$ found the mean ratio of AVD to PVD was 0.98. Unlike these studies, however, Kitzman and colleagues ${ }^{5}$ found the mean circumference of the aortic 

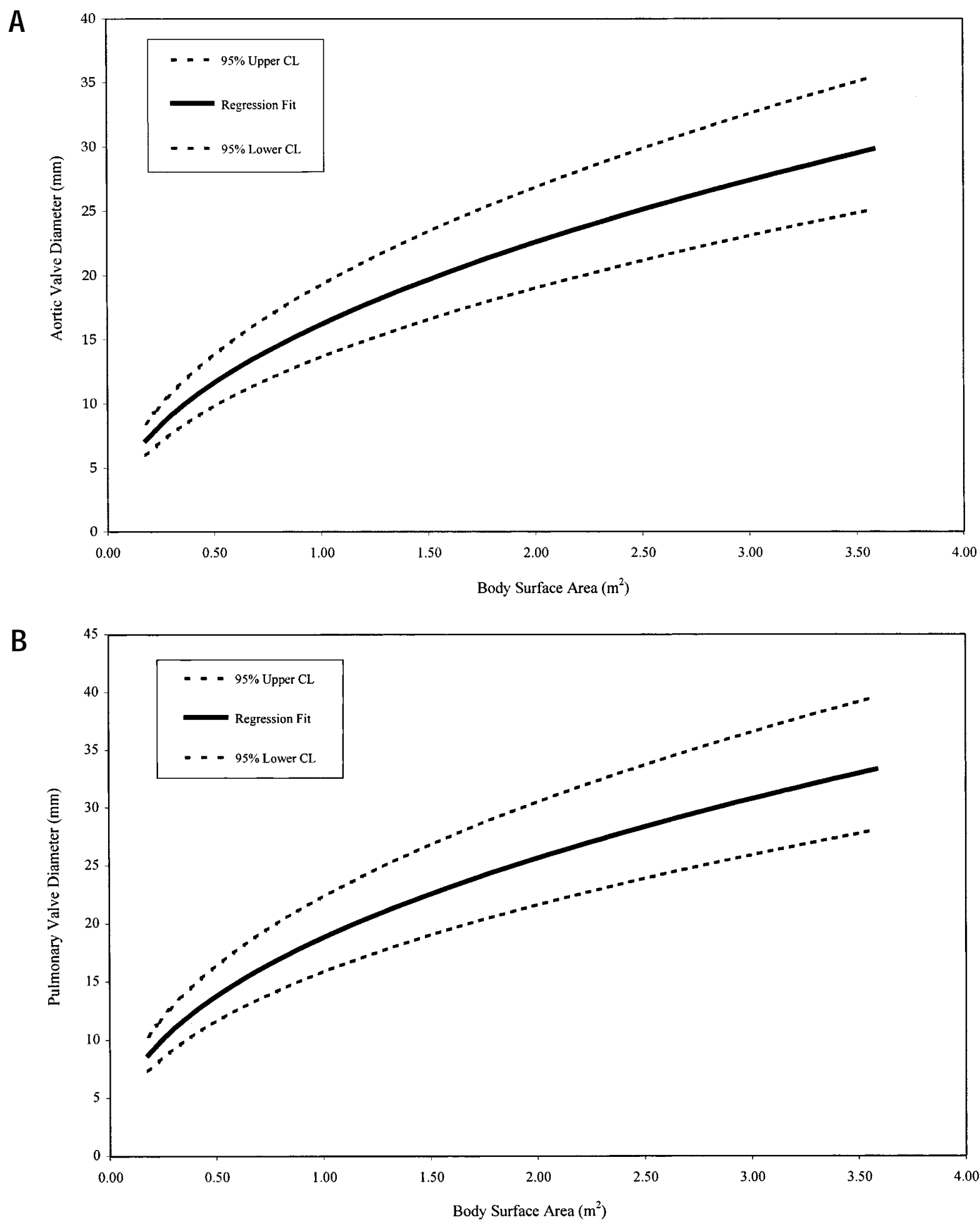

Fig 1. A, Regression data for the male subgroup relating aortic valve diameter $(n=2993)$ to body surface area. The solid middle line represents the point estimates and the two dashed outer lines enclose the $95 \%$ confidence intervals. B, Regression data for the male subgroup relating pulmonary valve diameter $(\mathrm{n}=3508)$ to body surface area. The solid middle line represents the point estimates and the two dashed outer lines enclose the $95 \%$ confidence intervals. 

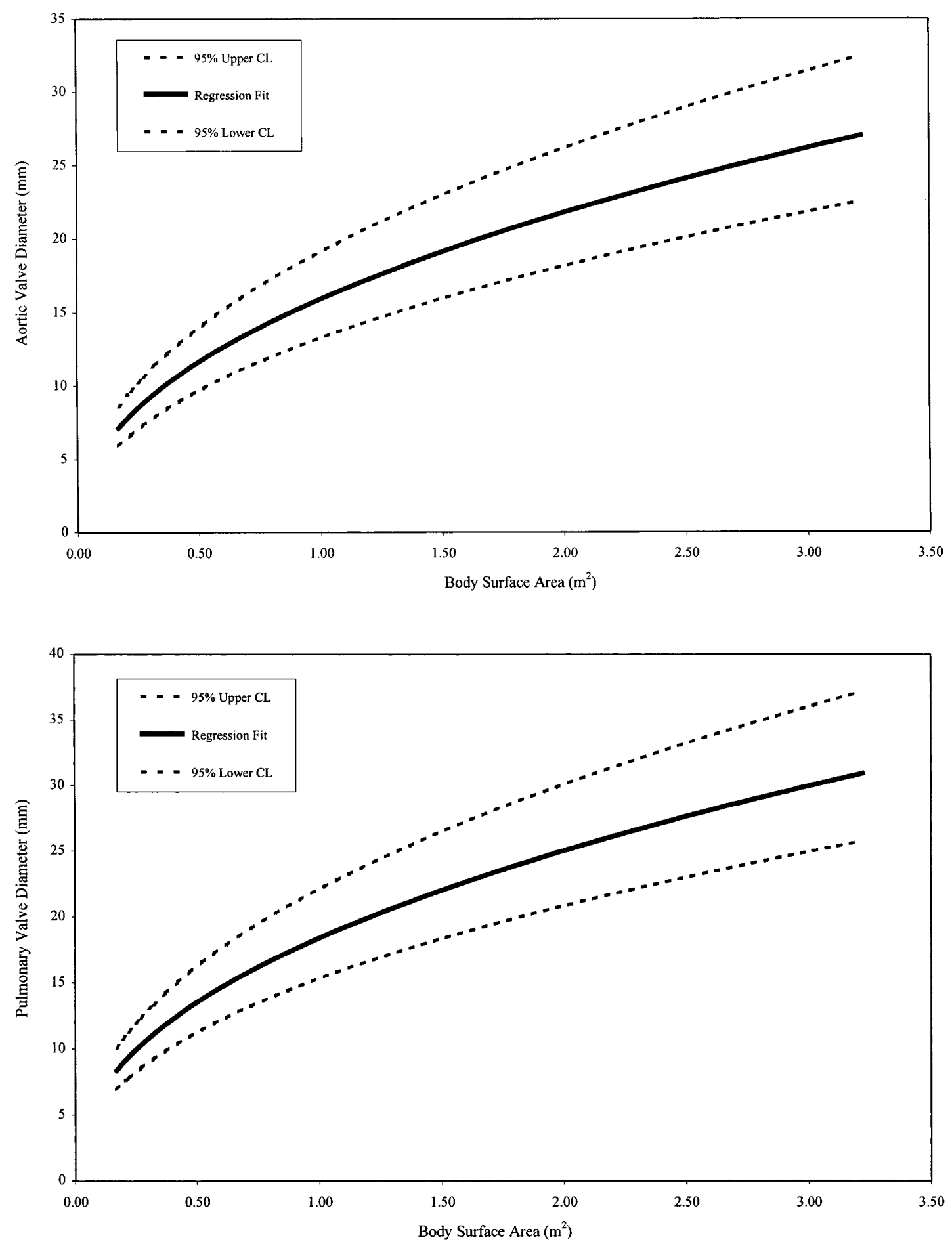

B

Fig 2. A, Regression data for the female subgroup relating aortic valve diameter $(n=1643)$ to body surface area. The solid middle line represents the point estimates and the two dashed outer lines enclose the $95 \%$ confidence intervals. B, Regression data for the female subgroup relating pulmonary valve diameter $(\mathrm{n}=1972)$ to body surface area. The solid middle line represents the point estimates and the two dashed outer lines enclose the $95 \%$ confidence intervals. 
valve surpassed that of the pulmonary valve by the fourth decade of life. In fact, the aortic valve circumference was found to approach that of the mitral valve by the 10th decade. In the current study, at no point was the mean AVD larger than the mean PVD. The mean AVD/PVD ratio remained under 0.9 for all male and female age groups.

The large sample size $(\mathrm{N}=6801)$ in this study should add a level of confidence for the surgeon in selecting the most beneficial prosthetic valve for each individual patient based on BSA. We believe that, used in conjunction with other clinically accepted evaluations, the BSA is a useful tool for estimating the normal AVD and PVD, providing important information for pediatric cardiologists, pediatric cardiac surgeons, adult cardiologists, and adult cardiac surgeons in many of their decision-making activities.

\section{REFERENCES}

1. Kirklin JW, Barratt-Boyes BG. Anatomy, dimensions, and terminology. In: Kirklin JW, Barratt-Boyes BG, editors. Cardiac surgery. 2nd ed. New York: Churchill Livingstone; 1993. p. 360.

2. Rowlatt UF, Rimoldi HJA, Lev M. The quantitative anatomy of the normal child's heart. Pediatr Clin North Am 1963;10:499588 .

3. Westaby S, Karp RB, Blackstone EH, Bishop SP. Adult human valve dimensions and their surgical significance. Am J Cardiol 1984;53:552-6.

4. Scholz DG, Kitzman DW, Hagen PT, Ilstrup DM, Edwards WD. Age-related changes in normal human hearts during the first 10 decades of life. Part I (growth): a quantitative anatomic study of
200 specimens from subjects from birth to 19 years old. Mayo Clin Proc 1988;63:126-36.

5. Kitzman DW, Scholz DG, Hagen PT, Ilstrup DM, Edwards WD. Age-related changes in normal human hearts during the first 10 decades of life. Part II (maturity): a quantitative anatomic study of 765 specimens from subjects 20 to 99 years old. Mayo Clin Proc 1988;63:137-46.

6. Eckner FAO, Brown BW, Davidson DL, Glagov S. Dimensions of normal hearts. Arch Pathol 1969;88:497-507.

7. Krovetz LJ. Age-related changes in size of the aortic valve annulus in man. Am Heart J 1990;5:569-74.

8. Sievers H-H, Onnasch DGW, Lange PE, Bernhard A, Heintzen $\mathrm{PH}$. Dimensions of the great arteries, semilunar valve roots, and right ventricular outflow tract during growth: normative angiocardiographic data. Pediatr Cardiol 1983;4:189-96.

9. Roman MJ, Devereux RB, Kramer-Fox R, O'Loughlin J. Twodimensional echocardiographic aortic root dimensions in normal children and adults. Am J Cardiol 1989;64:507-12.

10. Vasan RS, Larson MG, Levy D. Determinants of echocardiographic aortic root size. Circulation 1995;91:734-40.

11. Sheil MLK, Jenkins O, Sholler GF. Echocardiographic assessment of aortic root dimensions in normal children based on measurement of a new ratio of aortic size independent of growth. Am J Cardiol 1995;75:711-5.

12. Pearce WH, Slaughter MS, LeMaire S, Salyapongse AN, Feinglass J, McCarthy WJ, et al. Aortic diameter as a function of age, gender, and body surface area. Surgery 1993;114:691-7.

13. Haycock GB, Schwartz GJ, Wisotsky DH. Geometric method for measuring body surface area: a height-weight formula validated in infants, children, and adults. J Pediatr 1978;93:62-6.

14. Glantz SA. How to test for trends. In: A primer of biostatistics. New York: McGraw-Hill; 1997. p. 251-2.

15. Hopkins RA. Appendix — valve diameters. In: Hopkins RA, editor. Cardiac reconstructions with allograft valves. New York: Springer-Verlag; 1989. p. 189-90.

\section{Authoritative}

The Journal of Thoracic and Cardiovascular Surgery is the most frequently cited thoracic/cardiovascular surgery journal in the Science Citation Index. An article in JTCVS is sited on average almost twice as often as those in the closest cardiothoracic journal. 